
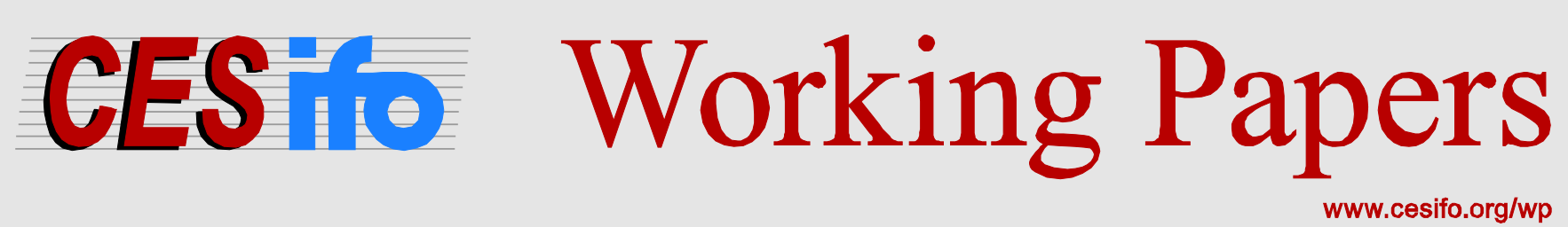

\title{
Lattices and Lotteries in Apportioning Risk
}

\author{
Harris Schlesinger
}

\author{
CESIFO WORKING PAPER NO. 5067 \\ CATEGORY 12: EMPIRICAL AND THEORETICAL METHODS \\ NOVEMBER 2014
}

An electronic version of the paper may be downloaded

- from the SSRN website:

- from the RePEc website:

- from the CESifo website:

www.SSRN.com

Www.RePEc.org

www.CESifo-group.org/wp

\section{CESifo}




\title{
Lattices and Lotteries in Apportioning Risk
}

\begin{abstract}
Although risk aversion has been used in economic models for over 275 years, the past few decades have shown how higher order risk attitudes are also quite important. A behavioral approach to defining such risk attitudes was developed by Eeckhoudt and Schlesinger (2006), based upon simple lottery preference. This article show how the mathematics of lattice theory can be used to model these lottery preferences. In addition to modeling a simple lattice structure, I show how such lattices can be extended in order to develop a better understanding of higher order risk attitudes.
\end{abstract}

JEL-Code: D810.

Keywords: risk apportionment, mixed risk aversion, mixed risk loving, lattice theory, submodular function.

\author{
Harris Schlesinger \\ Econimcs \& Finance Department \\ University of Alabama \\ P.O. Box 870224 \\ USA - 35487-0224 Tuscaloosa AL \\ hschlesi@cba.ua.edu
}

October 28, 2014

This paper is based on my Geneva Risk Lecture at the 41st annual meeting of the European Group of Risk and Insurance Economists, held in St. Gallen, Switzerland. For me personally, this was my 29th time to attend the EGRIE conference. I thank Sebastian Ebert, Günter Franke, Mike Hoy, Achim Wambach, Zhe Yang and EGRIE participants for helpful comments on an earlier draft of this paper. 


\section{INTRODUCTION}

My work together with Louis Eeckhoudt has always been productive and interesting, but never more so than when we first discovered how simple lottery preferences were able to explain higher order derivatives in expected utility models. Indeed, the idea was so simple that it is still puzzling why it was not discovered earlier. Moreover, since the lottery preference itself is a primitive, it need not relate to the expected utility paradigm; rather it is a model-free method to define attitudes toward higher order risk. ${ }^{2}$ The method of lottery construction for these preferences gave rise to the name "risk apportionment," since the comparative lotteries always seek the least harmful lottery state in which to add another unavoidable risk.

In Eeckhoudt and Schlesinger (2006), lottery preferences describing prudence (a third order risk attitude) and temperance (a fourth order risk attitude) are fairly simple. Higher order risk attitudes are obtainable by nesting lotteries. But while the procedure for obtaining these higher order attitudes is straightforward, much of the simplicity in the interpretations is lost.

A more general version of this risk apportionment approach is provided in Eeckhoudt, Schlesinger and Tsetlin (2009), who model lottery preference between added pairs of independent random variables. Each element in the pair consists of either a "good" or a "bad" random variable, where both "good" and "bad" are relative to each other, and the comparison is made via stochastic dominance of some order. ${ }^{3}$ In this set-up, the choices are easily modeled within a simple lattice.

While the above mentioned papers look at a univariate risk, extensions to a bivariate case are quite direct, as shown by Eeckhoudt, Rey and Schlesinger (2007), Tsetlin and Winkler (2009) and Jokung (2011). Eeckhoudt et al. (2007) briefly explain how their third- and fourth-order bivariate preference rankings can be modeled within a lattice, with an assumption of a submodular preference functional. My purpose in this article is to bring this lattice methodology to the forefront, and to expand it somewhat. In a sense, this lattice structure provides a type of "blueprint" for the construction of risk-apportionment lotteries.

\footnotetext{
2 I do realize that this claim is subject to interpretations of "the reduction of compound lotteries." As such, it is subject to many of the same behavioral criticisms as is expected utility theory.

${ }^{3}$ Eeckhoudt et al. (2009) also allow for the comparison of risks as in Ekern (1980).
} 
In particular, there is an extremely canonical lattice structure to describe preferences over the "good" with "bad" combinations as described above. Extensions to higher order risk preferences using this methodology can be shown to generate another canonical lattice structure. This extended lattice can then be augmented in two specific ways, and higher orders of risk preference are shown to be isometric to a preference ranking of these two augmentations.

In the next section, I start with a brief overview of the risk apportionment approach. ${ }^{4}$ I then show how this basic approach can be easily portrayed using a lattice structure. This approach allows for a nice generalization of the framework of Menezes and Wang (2005), who defined the concept of "outer risk" in their description of temperance. I next show how an existing lattice structure leads to a natural precedence ordering and how this precedence ordering can be used inductively to generate higher orders of risk apportionment. Whereas the paper assumes mostly that agents are mixed risk averse, as defined in Caballé and Pomansky (1995), I also show how the lattice concept is easily extended to examine mixed risk lovers, as defined by Crainich, Eeckhoudt and Trannoy (2013).

\section{OVERVIEW OF RISK APPORTIONMENT}

We consider here an economic agent who is mixed risk averse, with differentiable utility function of wealth $u$. Mixed risk aversion is defined by Caballé and Pomansky (1995) within expected utility models. Letting $u^{(n)}(w)$ denote the $n^{\text {th }}$ derivative of utility with respect to wealth, mixed risk aversion is characterized via $\operatorname{sgn} u^{(n)}(w)=-(1)^{n+1} \forall w$, for every strictly positive integer $n$. The agent is also endowed with some initial wealth $w$.

Eeckhoudt and Schlesinger (2006) provide a description of higher order risk attitudes as preference for "disaggregating the harms." To follow this approach, let $H_{1}$ and $H_{2}$ denote two "harms." I will define what we mean by "harms," but to start, let us say that $H_{1}$ and $H_{2}$ denote two sure losses of money. Let $[x, y]$ denote a 50-50 lottery that pays out either $x$ or $y$, each with an equally likely chance. In general, we will allow for $x$ and $y$ themselves be random, but for now we will assume that both $x=H_{1}$ and $y=H_{2}$ are negative constants. In this case, we can define risk aversion as a preference for the lottery $L \equiv\left[H_{1}, H_{2}\right]$ over the lottery $R \equiv\left[0, H_{1}+H_{2}\right]$. To be globally risk averse, this preference would need to hold for every $H_{1}$ and $H_{2}$ defined as negative constants and for every starting wealth $w^{5}$

This preference is illustrated in Figure 1. Here the lotteries are depicted in probability trees. The probabilities are not annotated, since each branch has a probability of $1 / 2$. A risk-averse

\footnotetext{
${ }^{4}$ A more complete overview, including some historical perspective, is presented in Eeckhoudt (2012)

5 To prevent bankruptcy complications, I will assume throughout that total wealth is positive with probability 1.
} 
individual always prefers lottery $L$ to lottery $R$. Indeed, it is trivial to show that lottery $R$ is a simple mean-preserving spread of lottery $L$, as defined by Rothschild and Stiglitz (1970), so that this characterization also works outside of expected utility theory. Under expected utility, this lottery-preference ranking requires utility to be concave.

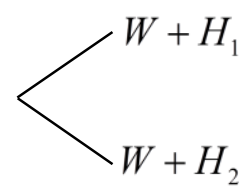

$L$

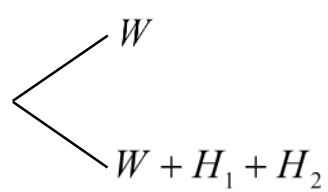

$R$

Figure 1: Lottery preference as risk apportionment

The third order risk attitude of prudence is now fairly well established in the literature. This attitude follows from the lottery preference above by allowing one of the two "harms," say $H_{2}$, to now be a zero mean risk. This is a "harm" only if the agent is risk averse. Indeed, defining prudence does not require risk aversion; but assuming risk aversion allows us to interpret the zero-mean risk as being bad, i.e. a "harm." With our reinterpretation of $H_{2}$, prudence is a preference for lottery $L$ over lottery $R$. In an expected utility setting, this is easily shown to be equivalent to a convex marginal utility, i.e. to $u^{\prime \prime \prime}(w)>0$.

If an agent owned the lottery $\left[0, H_{1}\right]$ and had to accept the harm $H_{2}$ in one state of the lottery, the prudent agent would always prefer to place the risk in the state with 0 , rather than the state with $H_{1}$. As was the case with risk aversion, this can be described as a preference for "disaggregating the harms."

To define the $4^{\text {th }}$ order risk attitude of temperance, we need only to change the harm $H_{1}$ to a second zero-mean risk that is statistically independent of $H_{2}$. For orders higher than 4 , Eeckhoudt and Schlesinger (2006) use a nesting process. Although this process is straightforward, it loses the intuitive appeal of "disaggregating the harms."

A more general approach was put forth in Eeckhoudt et al. (2009) and Tsetlin and Winkler (2009). Rather than consider "harms," this approach considers alternatives $G_{1}$ and $B_{1}$. Here it is assumed that $G_{1}$ dominates $B_{1}$ by stochastic dominance of some order $N_{1}{ }^{6}$ In this sense, we will refer to $G_{1}$ as the relatively good alternative and to $B_{1}$ as the relatively bad alternative. Note that both of these alternatives might be good or both might be bad. The descriptions of "good" and "bad" are only relative to one another. If we now allow for a second pair of alternatives $G_{2}$ and $B_{2}$, where it is assumed that $G_{2}$ dominates $B_{2}$ by stochastic dominance of some order $N_{2}$, then

\footnotetext{
${ }^{6}$ A comparison of $G_{1}$ and $B_{1}$ via increases in $N$ th degree risk, as defined by Ekern (1980), works in a similar manner. For the sake of concreteness, in this paper I only use the comparisons via stochastic dominance.
} 
Eeckhoudt et al. (2009) show that the lottery $L \equiv\left[G_{1}+B_{2}, B_{1}+G_{2}\right]$ dominates the lottery $R \equiv\left[G_{1}+G_{2}, B_{1}+B_{2}\right]$ via stochastic dominance of order $N_{1}+N_{2}$. If preferences display mixed risk aversion, we once again will have the lottery $L$ preferred to the lottery $R$. This behavior is thus described as a preference of "combining good with bad," as opposed to "combining good with good."

Note that for the Eeckhoudt and Schlesinger (2006) descriptions, we simply define $G_{1}$ and $G_{2}$ both as zero. We then have the "harms" $B_{1}$ and $B_{2}$, each of which is less preferred than zero. This approach also allows us to consider bivariate preferences, as done by Eeckhoudt et al. (2007) and by Jokung (2011). This follows in a straightforward manner by generalizing the above lotteries such that the lottery $L \equiv\left[\left(G_{1}, B_{2}\right),\left(B_{1}, G_{2}\right)\right]$ dominates the lottery $R \equiv\left[\left(G_{1}, G_{2}\right),\left(B_{1}, B_{2}\right)\right]$, where dominance is defined here via a bivariate concave stochastic order. The general case is depicted in Figure 2, where bivariate risk apportionment is equivalent to a preference for lottery $L$ over lottery $R$, which must hold for all such $L$ and $R$ pairs and for all initial endowments in each of the two dimensions.

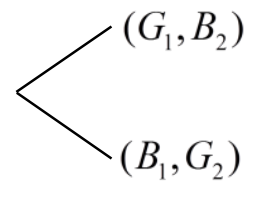

$L$

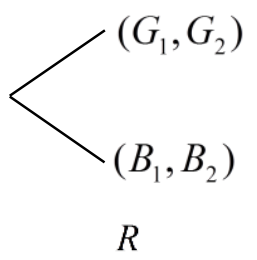

Figure 2: Bivariate lottery preference as risk apportionment

For applications and economic interpretations of the above results, one can turn to the original papers. My purpose here is to analyze risk apportionment via the use of lattices, which I turn to next.

\section{RISK APPORTIONMENT IN A LATTICE STRUCTURE}

The above analysis gives rise to two canonical partial orderings $\succ$, which we can loosely interpret as "is preferred to." In particular:

$$
\left(G_{1}, G_{2}\right) \succ\left(G_{1}, B_{2}\right) \succ\left(B_{1}, B_{2}\right) \quad \text { and } \quad\left(G_{1}, G_{2}\right) \succ\left(B_{1}, G_{2}\right) \succ\left(B_{1}, B_{2}\right)
$$


Note that the pairs $\left(G_{1}, B_{2}\right)$ and $\left(B_{1}, G_{2}\right)$ are not directly comparable to each other without knowing their specifics. We can now define the "join" of any two pairs $x \equiv\left(x_{1}, x_{2}\right)$ and $y \equiv\left(y_{1}, y_{2}\right)$ as a pair containing the maximum of each element. We define the "meet" as the pair containing the minimum of each element. In general, a maximum and minimum need not exist for two pairs chosen arbitrarily. But for our good-bad pairs as defined here, the minimum and maximum are defined by the same criteria used to rank $G_{i}$ with $B_{i}$ above.

Using the customary notation, we have

Join: $\quad\left(x_{1}, x_{2}\right) \vee\left(y_{1}, y_{2}\right) \equiv\left(\max \left(x_{1}, y_{1}\right), \max \left(x_{2}, y_{2}\right)\right)$

Meet: $\quad\left(x_{1}, x_{2}\right) \wedge\left(y_{1}, y_{2}\right) \equiv\left(\min \left(x_{1}, y_{1}\right), \min \left(x_{2}, y_{2}\right)\right)$.

As examples, we have the simple relations:

$$
\begin{aligned}
& \left(G_{1}, B_{2}\right) \vee\left(G_{1}, G_{2}\right) \equiv\left(G_{1}, G_{2}\right) \\
& \left(G_{1}, B_{2}\right) \vee\left(B_{1}, G_{2}\right) \equiv\left(G_{1}, G_{2}\right)
\end{aligned}
$$

and

$$
\left(G_{1}, B_{2}\right) \wedge\left(B_{1}, G_{2}\right) \equiv\left(B_{1}, B_{2}\right)
$$

We can now draw a directed graph to illustrate the partial orderings in (1). Figure 3 depicts these two distinct partial orderings. ${ }^{7}$ Since every pair in the graph has a join and a meet, this structure is known as a "lattice." The two partial orderings given in (1) are depicted by the connected paths in Figure 3, each of which is referred to as a "chain."

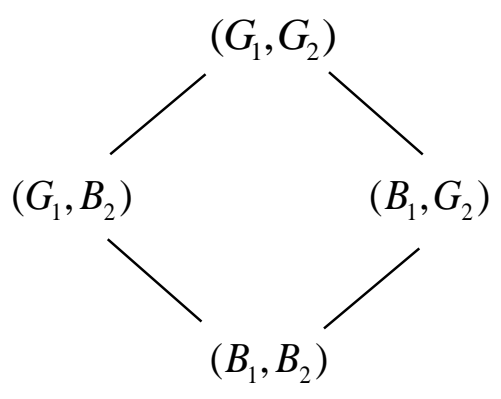

Figure 3: A preference lattice

\footnotetext{
7 By convention, the "direction" of the links is considered downward and I do not include arrows in the graph to
} indicate this direction. For more particulars about orderings, graphs and lattices, see Roman (2008). 
Bivariate risk apportionment is simply a preference for a gamble between $\left(G_{1}, B_{2}\right)$ and $\left(B_{1}, G_{2}\right)$ versus a gamble between their meet, $\left(B_{1}, B_{2}\right)$, and their join, $\left(G_{1}, G_{2}\right)$. Univariate risk apportionment is just a special case in which the elements of each pair are in the same dimension and are added together.

Considering the two partial orderings in (1), we can mimic the terminology of Menezes and Wang $(2005)^{8}$ and refer to $\left(G_{1}, B_{2}\right)$ and $\left(B_{1}, G_{2}\right)$ as the "inner risks," and also refer to $\left(G_{1}, G_{2}\right)$ and $\left(B_{1}, B_{2}\right)$ as the "outer risks." Risk apportionment can be described as a preference for a 50 50 gamble between the two inner risks, as opposed to a 50-50 gamble between the two outer risks. It's as simple as that!

Let $V(x)$ denote a preference function, such as expected utility, where $x$ can be either one dimensional, or can denote a pair of attributes. The function $V$ is submodular if

$$
\frac{1}{2} V(x)+\frac{1}{2} V(y) \geq \frac{1}{2} V(x \vee y)+\frac{1}{2} V(x \wedge y) \forall x, y \cdot 9
$$

The function is supermodular if the inequality in (3) is reversed. Letting $V$ denote utility, we see that risk apportionment is equivalent to one's having a submodular preference function. The case where preferences are supermodular can be linked to risk loving behavior and will be examined later in this article.

\section{INDUCTING TO HIGHER ORDERS OR MULTIPLE ATTRIBUTES}

Consider the basic risk apportionment lattice in Figure 3. Suppose that we now wish to add a third set of prospects $\left\{G_{3}, B_{3}\right\}$. We assume that $G_{3}$ dominates $B_{3}$ by stochastic dominance of $\operatorname{order} N_{3}$. These can either be in a new third dimension or they can be added to the totals within a single dimension. We only need to assume that any randomness in these prospects is independent of the risk in the other prospects. Suppose that one of these prospects must be added to the two inner risks in Figure 3, while the other is then added to the two outer risks. Risk apportionment then requires that adding $B_{3}$ to the "good" inner-risk lottery (and $G_{3}$ to the "bad" outer-risk lottery) is preferred to the reverse.

This leads to a more complicated lattice as depicted in Figure 4. Note first of all that Figure 4 is indeed a lattice, since every pair of elements has both a join and a meet. Also note that there are

\footnotetext{
8 Menezes and Wang(2005) use this terminology in describing temperance, which they demonstrate via an equivalence proof to fourth order stochastic dominance rankings.

9 The scalar multiple of $1 / 2$ on each term is unnecessary. It is include here only to give an interpretation as an expectation of $V$, using our 50-50 lotteries.
} 
six distinct chains in this lattice. This lattice is an example of the oft used "power set lattice." This is seen by considering only the bad alternatives $B_{i .}{ }^{10}$ The understanding here is that if a bad alternative is not included in the set, then the good alternative is used in its place. Clearly, our partial ordering can viewed as set inclusion, where the sets are the sets of bad alternatives. For example, consider the chain highlighted by the darker edges in Figure 4. Looking at only the bad alternatives we obtain a partial ordering via set inclusion as $\varnothing \subset\left\{B_{2}\right\} \subset\left\{B_{2}, B_{3}\right\} \subset\left\{B_{1}, B_{2}, B_{3}\right\}$. This explains the description as a "power set lattice."

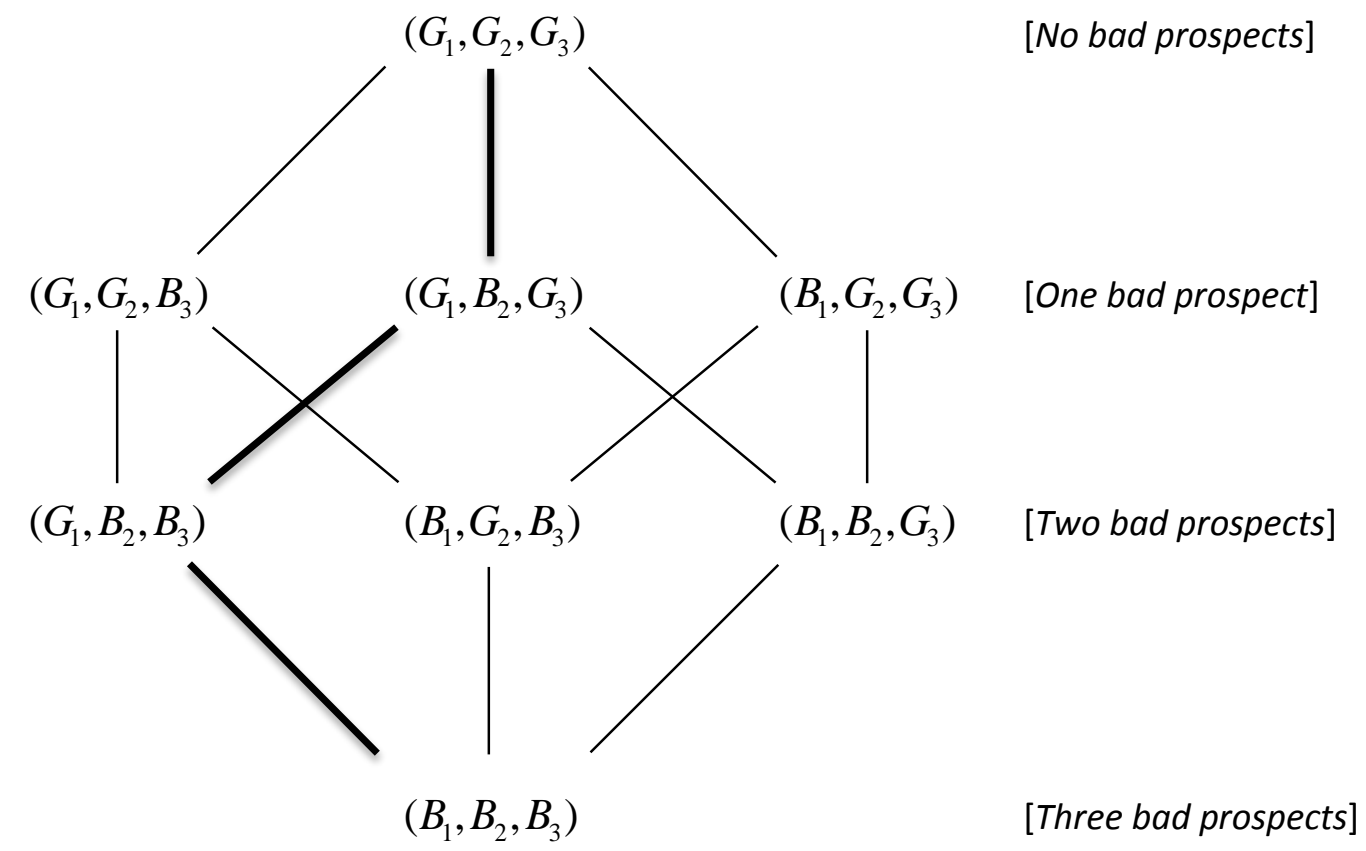

Figure 4: Extended preference lattice

As a matter of terminology, I will refer to the four levels of outcomes in the Figure 4 lattice as "tiers." Tier 1 contains only $\left\{\left(G_{1}, G_{2}, G_{3}\right)\right\}$. Tier 2 contains $\left\{\left(G_{1}, G_{2}, B_{3}\right),\left(G_{1}, B_{2}, G_{3}\right),\left(B_{1}, G_{2}, G_{3}\right)\right\}$. Tier 3 contains $\left\{\left(G_{1}, B_{2}, B_{3}\right),\left(B_{1}, G_{2}, B_{3}\right),\left(B_{1}, B_{2}, G_{3}\right)\right\}$. And tier 4 contains only $\left\{\left(B_{1}, B_{2}, B_{3}\right)\right\}$. Although we cannot always compare elements between different tiers, each element in tier $j$ is dominated by some element in tier $j-1$ for $j=2,3,4$. Note that tier $j$ contains exactly $j-1$ bad prospects for each $j$.

\footnotetext{
${ }^{10}$ We could just as easily consider only the good alternatives. Using the bad alternatives provides for an easier comparison to Eeckhoudt and Schlesinger (2006).
} 


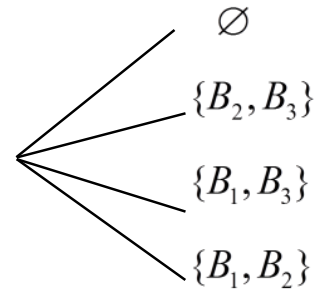

$L$

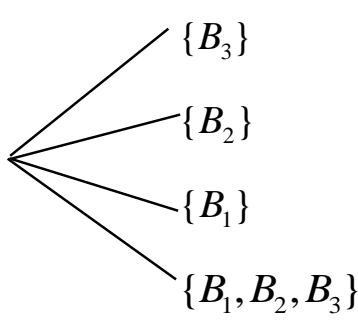

$R$

Figure 5: Three prospect risk apportionment

Now consider a 50-50 lottery between the "inner risk lottery" and the "outer risk lottery" in Figure 3. In reduced form, this yields a lottery with four equally outcomes. Adding $G_{3}$ to the outer risks in Figure 3 and adding $B_{3}$ to inner risks, these four equally likely outcomes are those from tier 1 in Figure 4 ("no bad prospects") together with those from tier 3 ("two bad prospects"). The alternative lottery, adding $B_{3}$ to the outer risks in Figure 3 and adding $G_{3}$ to inner risks, yields a lottery with the four outcomes from the second and fourth tiers in Figure 4. In other words, risk apportionment is equivalent to a preference for the equal-probability fourprospect lottery between no bad prospects or a combination of two of the bad prospects vis-à-vis the lottery between combinations of one bad prospect or all three bad prospects. Using our set notation, this yields a preference for lottery $L$ over lottery $R$ in Figure 5 . In the case of uniattribute preferences, the risk apportionment is of order $N_{1}+N_{2}+N_{3}$.

\section{$\underline{\text { An Example }}$}

While the general methodology in Figure 4 is useful, an example might help to illustrate its use. Let us return to the simpler set-up in Eeckhoudt and Schlesinger (2006) and suppose that the harm $B_{1}$ is a negative constant, say $B_{1}=-k$. We assume that $B_{2}=\tilde{\varepsilon}_{2}$ and $B_{3}=\tilde{\varepsilon}_{3}$ are independently distributed zero mean risks. All three good alternatives are assumed to be zero. Preferences are uniattrubute and the relevant good and bad alternatives are summed in any outcome. The above analysis would thus describe risk apportionment of order 5.

The four-outcome lottery with no harm or two harms (lottery $L$ in Figure 5) is preferred to the four-outcome lottery with one harm or three harms (lottery $R$ in Figure 5) if the individual is "edgy" (i.e. risk apportionate of order 5) ${ }^{11}$. This is shown in Figure 6, which is a special case of Figure 4.

11 The term "edgy" first appears in Lajeri-Chaherli (2004). 


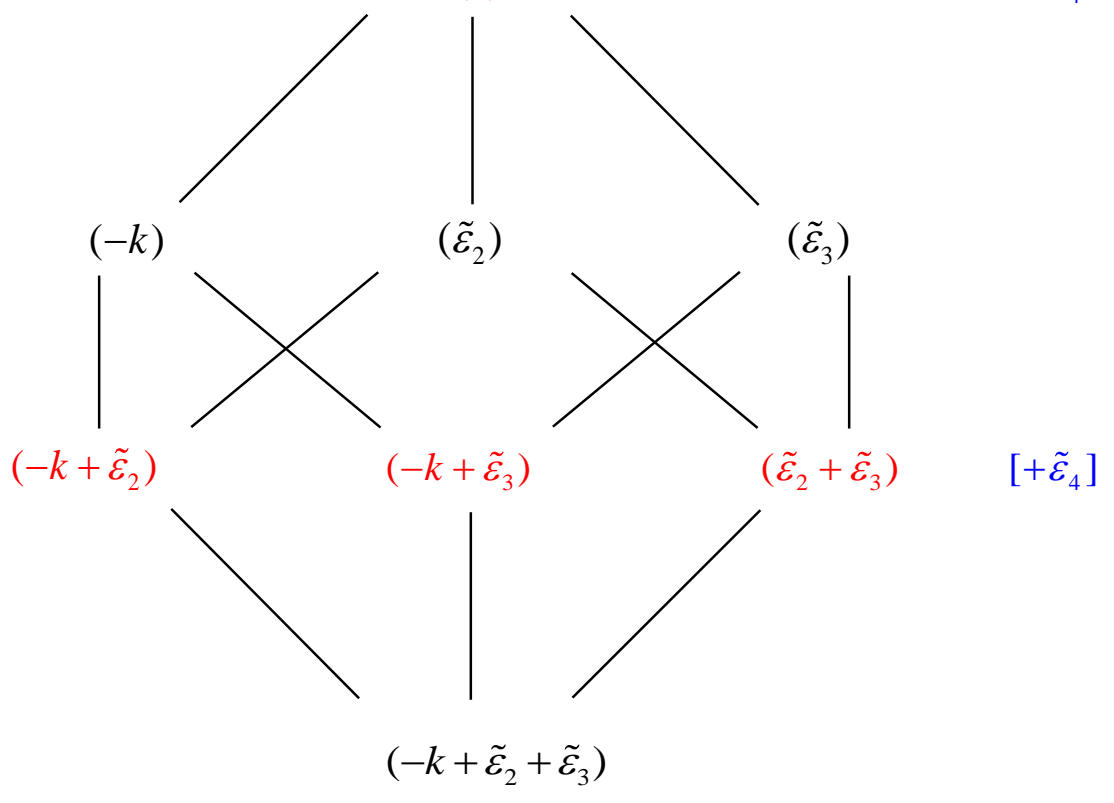

Figure 6: From R.A. 5 to R.A. 7 as a lottery preference

To expand to a higher order, allow for a 50-50 lottery between the two competing four-outcome lotteries above. That is, with a 50\% chance the payoff is the lottery between the elements in the first and third tiers in the lattice (the preferred outcome) and with a 50\% chance the payoff is the lottery between the elements in the second and fourth tiers in the lattice (the less desirable outcome). Now consider a new unavoidable "harm," namely another independent zero-mean risk $B_{4}=\tilde{\varepsilon}_{4}$. Since $B_{4}$ is dominated by zero via second-order stochastic dominance, this is a second-order harm. Suppose this harm must be added to one of the two branches in our 50-50 lottery. Since we started with a lattice depicting risk apportionment of order 5, R.A. 5, and since we now add a second-order harm, we are considering risk apportionment of order $7(=5+2)$.

R.A. 7 is equivalent to preference for adding $B_{4}=\widetilde{\varepsilon}_{4}$ to each outcome in the more preferred branch of the lottery. This is also annotated in Figure 6. The more preferred lottery is an eightoutcome lottery, where each outcome has equal probability. The eight outcomes are illustrated in Figure 7.

It is interesting to decompose what would happen if we shifted the placement of $\tilde{\varepsilon}_{4}$. The drawn lottery is more preferred than if we switch the placements of all of the $\tilde{\varepsilon}_{4}$ harms. Note that switching the placement can be decomposed into two effects as follows. 


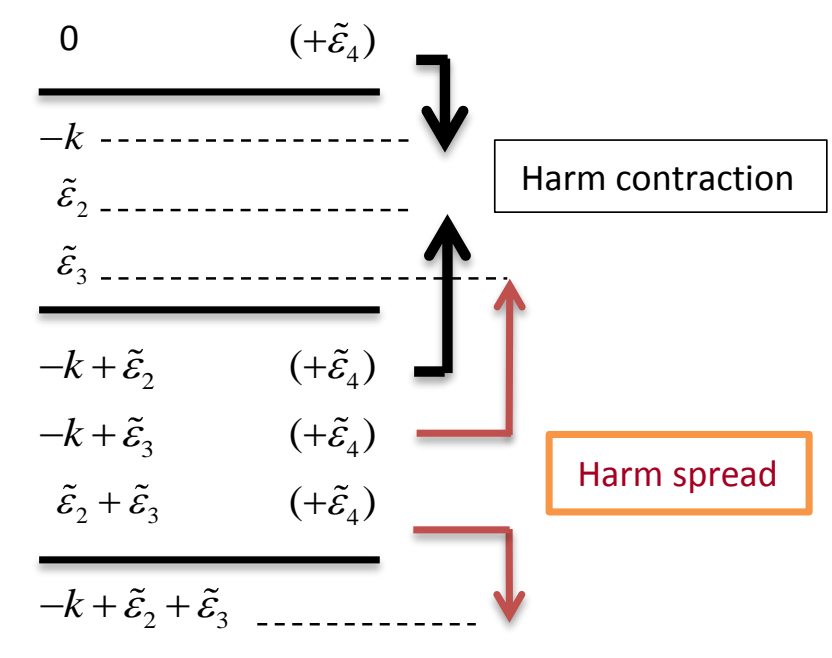

Figure 7: R.A. 7 via a precedence relation

For the first effect, one of the $\tilde{\varepsilon}_{4}$ risks is taken from the tier 1 and moved to the second tier and another is taken from the third tier and moved to the second tier. This is illustrated by the pair of dark arrows in Figure 7. In particular, we move $\tilde{\varepsilon}_{4}$ from 0 to $-k$ and we simultaneously move $\tilde{\varepsilon}_{4}$ from $-k+\tilde{\varepsilon}_{2}$ to $\tilde{\varepsilon}_{2}$. I will label the redistribution from outer tiers (tier 1 and tier 3 ) to an inner tier (tier 2) as a "harm contraction." This particular harm contraction will be welfare increasing to any agent who is prudent. To see this, consider only these four outcomes. We have only to compare the 50-50 lotteries $\left[\tilde{\varepsilon}_{4}+0, \tilde{\varepsilon}_{4}-k+\tilde{\varepsilon}_{2}\right]$ and $\left[\tilde{\varepsilon}_{4}-k, \tilde{\varepsilon}_{4}+\tilde{\varepsilon}_{2}\right]$. Since $\tilde{\varepsilon}_{4}$ is in every branch, we can effectively take it out and add it to wealth $w$. Clearly the second lottery is then easily seen to be preferred by all prudent agents. This harm contraction is welfare increasing.

For the second effect, one of the $\tilde{\varepsilon}_{4}$ risks is taken from tier 3 and moved to tier 2 and another is taken from tier 3 and moved to tier 4 . This is illustrated by the pair of lighter arrows in Figure 7. I will refer to this as a "harm spread." Considering only these four outcomes, the lottery comparisons would be between the 50-50 lotteries $\left[\widetilde{\varepsilon}_{3}+\widetilde{\varepsilon}_{4}-k, \widetilde{\varepsilon}_{3}+\widetilde{\varepsilon}_{4}+\widetilde{\varepsilon}_{2}\right]$ and $\left[\tilde{\varepsilon}_{3}+\tilde{\varepsilon}_{4}+0, \tilde{\varepsilon}_{3}+\tilde{\varepsilon}_{4}-k+\tilde{\varepsilon}_{2}\right]$. A prudent agent would always prefer the first of these two lotteries, which is seen by removing the common $\tilde{\varepsilon}_{3}+\tilde{\varepsilon}_{4}$ from all of the branches. This harm spread is welfare decreasing.

So how do we value the aggregate of these two shifts taken in tandem? Since the harm spread is at a lower set of tiers and the harm contraction is at a higher set of tiers, we have a type of precedence relation. The spread occurs in "worse tiers" while the contraction occurs in "better tiers." For someone who is risk apportionate of order 7, the net effect on welfare is negative. 
An explanation of why this occurs can be found in Ebert and Schlesinger (2014). In all of the lotteries above, we look at the value of apportioning the third order risk from $\left[0,-k+\widetilde{\varepsilon}_{2}\right]$ to $\left[-k, \tilde{\varepsilon}_{2}\right]$. But with the spread, the background wealth contains $\tilde{\varepsilon}_{3}+\tilde{\varepsilon}_{4}$, whereas for the contraction the background wealth contains only $\tilde{\varepsilon}_{3}$. As a result, risk apportionment is more important (a larger change in welfare) for the harm spread than for the harm contraction. Hence, the net effect of the harm spread and the harm contraction taken in tandem is an overall reduction in welfare.

Although this precedence relation as shown here was for a specific example, it also holds for the general lattice structure illustrated in Figure 4, although the details are somewhat complex. For example, the general case might have multiattribute preferences. Moreover the "harms" would need to be replaced with the relatively bad alternatives, and the relatively good alternatives would take the place of zero.

\section{BUT WHAT ABOUT MIXED RISK LOVERS?}

This analysis thus far has been all about agents who are risk apportionate. Such agents exhibit what Caballé and Pomansky (1995) call "mixed risk aversion" in an expected utility framework. But what about agents who are risk lovers? In a thought-provoking paper, Crainich, Eeckhoudt and Trannoy (2013) show that risk lovers can also be prudent. ${ }^{12}$ Such behavior was supported empirically in recent experiments by Deck and Schlesinger (2014) and by Ebert and Wiesen (2014). In particular, these papers consider individuals who prefer to combine "good with good" and "bad with bad," as opposed to the risk-apportionate agents who prefer combining "good with bad." In this section, I set out a "blueprint" for extending the lattice analysis above to the case of mixed risk lovers.

Given the lattice structure in Figure 3, such mixed-risk-loving agents will have preference function that exhibits supermodularity, rather than the submodularity of preferences for mixed risk averters. At the same time, which of two lotteries is considered relatively good or bad might differ between mixed risk averters and mixed risk lovers.

Indeed, these lottery preferences agree on odd orders and disagree on even orders. Thus the mixed risk lover is risk apportionate for every odd order (prudence, edginess, etc.), but is "antirisk apportionate" for every even order (risk loving, intemperate, etc.). We can illustrate this with simple examples based on Figure 1, each of which generates prudence.

\footnotetext{
12 But, as was aptly pointed out by Ebert (2013), there is no compelling reason why risk aversion per se would be a
} cause of prudence. 


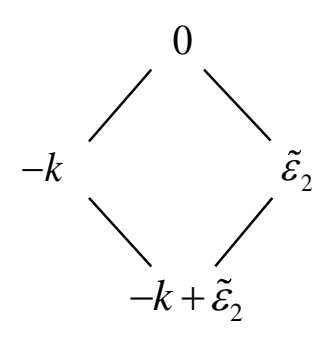

RISK AVERTER

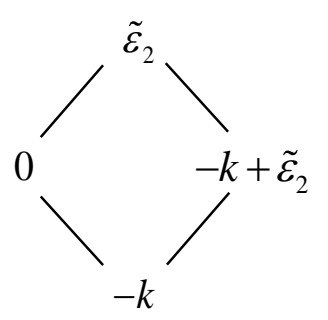

RISK LOVER

Figure 8: Prudence for risk averters and for risk lovers

The lattice on the left for Figure 8 is the simple lattice in Figure 3, where both good alternatives are zero. For the right-side lattice, we consider a risk lover. For this agent the zero-mean risk $\tilde{\varepsilon}_{2}$ is preferred to zero. In other words, $\tilde{\varepsilon}_{2}$ is relatively good, while zero is relatively bad. We assume that both types like zero better than losing money, $-k$. Hence, the chains for each type agent are completely different. For the risk averter, submodularity of preferences means that the $50-50$ lottery $\left[-k, \tilde{\varepsilon}_{2}\right]$ is preferred to the 50-50 lottery $\left[0,-k+\tilde{\varepsilon}_{2}\right]$, which defines prudence. This economic agent prefer the 50-50 lottery of the inner risks. But supermodularity of preferences for the risk lover implies the same lottery preference! This economic agent prefers the 50-50 lottery of the outer risks. Hence, both types of agents are prudent.

It is straightforward to extend the analysis here to the case where we consider risk apportionment of order 5. Redrawing the more general "power set lattice" from Figure 6 for the case of a mixed risk lover, we obtain the lattice in Figure 9.

Looking at the primitives here, the sure loss of $-k$ is a bad for both types of agents. The zero mean risks are now relatively good for the mixed risk lover. Thus, any node in the graph that replaces one zero mean risk with the other has not changed the good-bad mixture ratio. For example the node with only $\left(\tilde{\varepsilon}_{3}\right)$ contains one bad and two good outcomes for both mixed averters and mixed risk lovers. So does the node $\left(\tilde{\varepsilon}_{2}\right)$. On the other hand, any node that replaces $\tilde{\varepsilon}_{2}+\tilde{\varepsilon}_{3}$ with zero is replacing two goods with two bads. Thus, a careful comparison of Figure 9 with Figure 6 shows that they differ by only two node swaps. One is to swap $\left(\tilde{\varepsilon}_{2}+\tilde{\varepsilon}_{3}\right)$ with $(0)$. The other is to swap $\left(-k+\tilde{\varepsilon}_{2}+\tilde{\varepsilon}_{3}\right)$ with $(-k)$. But note that one of these swaps is between tier 1 and tier 3, while the other is between tier 2 and tier 4 . The precedence relation still dictates that a four-outcome lottery between the tier 1 and tier 3 outcomes is preferable to the four-outcome lottery between the tier 2 and tier 4 outcomes. This lottery preference is identical for both mixed risk averters (Figure 6) and mixed risk lovers (Figure 9). 


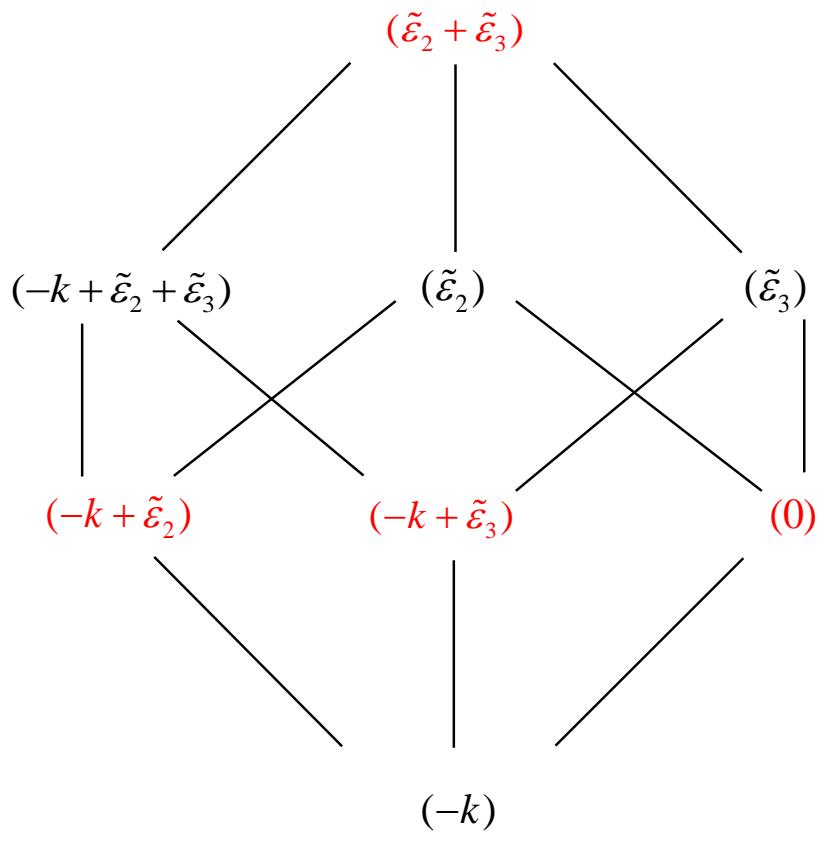

Figure 9: R.A. of order 5 for the mixed risk lover

This same result would not hold true for an even order of risk apportionment. For instance, we consider risk apportionment of order 6 by having three "harms" and replacing $-k$ with the independent zero-mean risk $\tilde{\varepsilon}_{1}$. Of course this "harm" will be relatively good for the risk lover. The respective power set lattices for the mixed risk averter and for the mixed risk lover are both given in Figure 10.

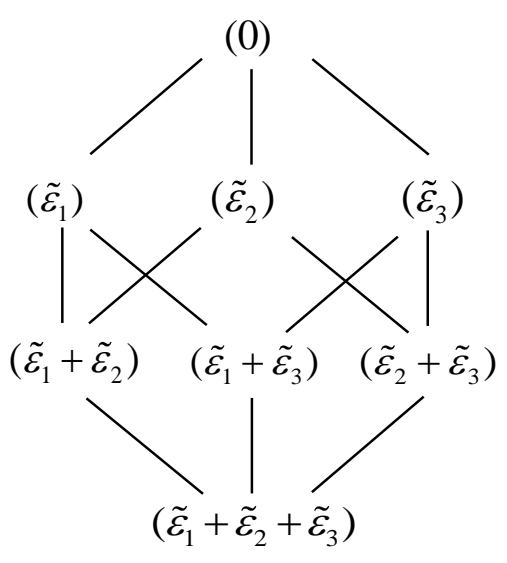

Mixed Risk Averter
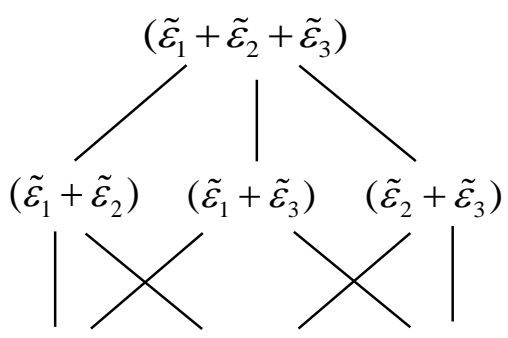

$\left(\tilde{\varepsilon}_{1}\right)$

$\left(\tilde{\varepsilon}_{2}\right)$
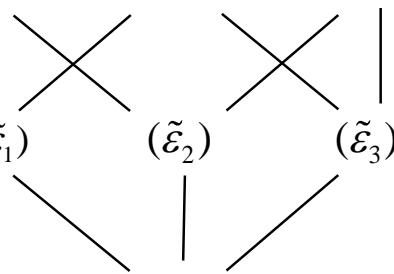

(0)

Mixed Risk Lover

Figure 10: R.A. of order 6 for each type of agent 
Since all three good-versus-bad pairs are switched, it should not be surprising that the preference chains for mixed risk averters and mixed risk lovers are completely reversed. Thus, the R.A. 6 lattice for mixed risk lovers is the so-called "dual lattice" for the one for mixed risk averters. The precedence relation over four-outcome lotteries (tiers 1 and 3 are preferred to tiers 2 and 4) thus yields completely opposite lottery preferences for the two types. Mixed risk averters are risk apportionate of order 6 , whereas mixed risk lovers are anti-risk apportionate of order 6 .

\section{CONCLUDING COMMENTS}

Higher order risk preferences are still a relatively nascent area of research. While the notion of risk aversion has been around for a few hundred years, higher orders have only come under investigation more recently. My work with Louis Eeckhoudt in this area has hopefully given us new tools to think through these higher orders. But change takes time. Our better understanding of the concept of prudence has helped it to slowly find its way into mainstream economics. And, as we begin to understand temperance, we should see more and more implications of temperance (and intemperance) within models of economic choice.

The purpose of this article was to show how much of the modern methodology fits rather nicely within a simple lattice structure. While lattices are not something that are at the forefront of most economists' "bag of tricks," they are certainly not difficult to understand. This tool seems to be a nice way to illustrate good-with-bad types of preference rankings. Likewise, it graphically shows us how to generalize the "inner risks" and "outer risks" of Menezes and Wang (2005).

For expansions into non-expected utility models, these lattices provide us with a good place to start. Risk apportionment, i.e. mixed risk aversion, for example, requires only that preferences be submodular over such lattices. Mixed risk loving behavior requires supermodularity of preferences. ${ }^{13}$ Hopefully, many such expansions will be forthcoming.

\section{REFERENCES}

Caballé , J. and A. Pomansky, 1995. "Mixed Risk Aversion.” Journal of Economic Theory 71, 485-513.

Crainich, D., L. Eeckhoudt and A. Trannoy, 2013. "Even (Mixed) Risk Lovers are Prudent." American Economic Review 103, 1529-1535.

${ }^{13}$ For more information on submodularity and supermodularity, see the classic treatise by Topkis (1998). 
Deck, C. and H. Schlesinger, 2014. "Consistency of Higher Order Risk Preferences." Econometrica 82, 1913-1943.

Ebert, S., 2013. "Even (Mixed) Risk Lovers are Prudent: Comment.” American Economic Review 103, 1536-1537.

Ebert, S. and H. Schlesinger, 2014. "Comparative Risk Apportionment.” Working Paper.

Ebert, S. and D. Wiesen, 2014. “Joint Measurement of Risk Aversion, Prudence and Temperance.” Journal of Risk and Uncertainty 48, 231-252.

Eeckhoudt, L., 2012. "Beyond Risk Aversion: Why, How and What's Next." Geneva Risk and Insurance Review 37, 141-155.

Eeckhoudt, L. and H. Schlesinger, 2006. "Putting Risk in its Proper Place.” American Economic Review 96, 280-289.

Eeckhoudt, L., H. Schlesinger and I. Tsetlin, 2009. "Apportioning of Risks via Stochastic Dominance." Journal of Economic Theory 144, 994-1003.

Eeckhoudt, L., B. Rey and H. Schlesinger, 2007. “A Good Sign for Multivariate Risk Taking.” Management Science 53, 117-124.

Ekern, S., 1980. "Increasing N ${ }^{\text {th }}$ Degree Risk.” Economics Letters 6, 1980, 329-333.

Jokung, O., 2011. "Risk Apportionment via Bivariate Stochastic Dominance." Journal of Mathematical Economics 47, 448-452.

Lajeri-Chaherli, F., 2004. "Proper Prudence, Standard Prudence and Precautionary Vulnerability." Economics Letters 82, 29-34.

Menezes, C. and X. Wang, 2005. "Increasing Outer Risk." Journal of Mathematical Economics $41,875-886$.

Roman, S., 2008. Lattices and Ordered Sets. Springer: New York.

Topkis, D.M., 1998. Supermodularity and Complementarity. Princeton University Press: Princeton N.J.

Tsetlin, I. and R. Winkler, 2009. "Multiattribute Utility Satisfying a Preference for Combining Good with Bad.” Management Science 55, 1942-1952. 